\title{
Memory Sharing Practices in Turkish Families: The Effects of Parenting Styles on Memory Sharing Practices
}

IZMiR-1982

\section{INTRODUCTION}

Autobiographical memory (AM) is a special (Conway and Pleydell-Pearce 2000) and AMs can be simply defined as the recollection of personal events from one's own past (Tulving 1972). Recently, issues related to autobiographical memory such as collective memory, the parent-child conversation styles during recollection, reminiscing differences across cultures have also been examined from a social psychological perspective, there is a limited number of studies on memory sharing practices. type of memory strongly linked to emotions

\section{METHOD}

Study 1 consisted of parents $(N=223)$ between the ages of 40 and 65 living in Aegean Region and Study 2 was carried out with university students $(N=$ $182)$ aged between 18 and 25 years.

\section{RESULTS}

When the findings are examined, it is noteworthy that adults are more willing than young people to extract the necessary messages from shared memories and apply them in life .

When your family members tell their memories, can you remove the necessary messages and apply them in your life?

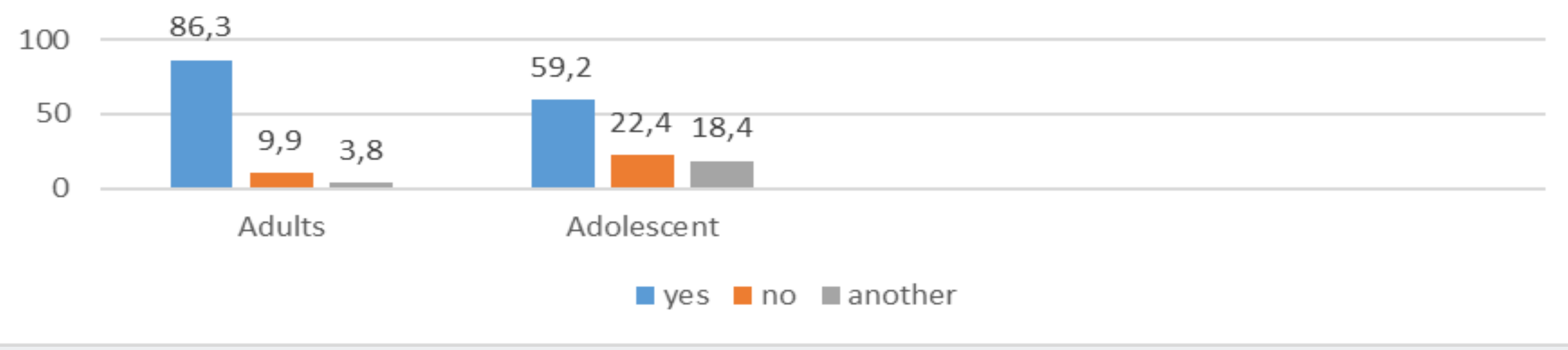

However, it is understood that adults who are eager to extract messages from memories do not show the same enthusism to listen to the memories and try to tell their own memories.

When the general emotion pattern of the memories shared in the family is examined; fathers avoid sharing memories that make them feel bad with their children, and they prefer content with funny, happiness and pride themes.In addition to these themes, mothers also include memories with sadness, anger and shame.
In the pattern of intra-family sharing memories in Turkey to be examined; it is seen that parents play more speaking roles and children play listeners.

$$
\text { I'm more of a listener in the family sharing moment. }
$$

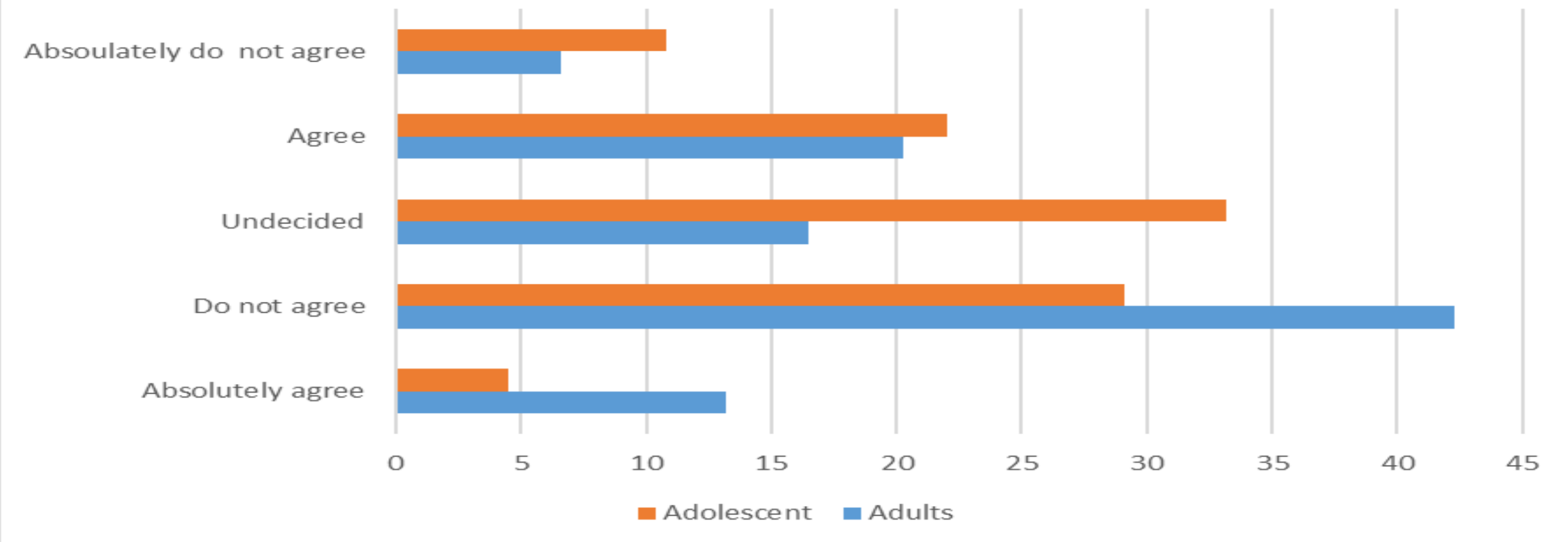

\section{DISCUSSION}

The content of shared memories and differences in narrator and listener roles were examined in the context of family roles (e.g. mother, father, daughter, or son). Results revealed that the parenting styles had a significant effect on the contributions of children to family conversations about the past events and the content of shared memories.On the other hand, is still in a geography where it is insisted of traditional gender roles influence in Turkey, told the memories of their mothers and fathers could be reflected until the content. This may suggest that the sharing of family memories has a negative effect on maintaining traditional gender roles. The findings of the present studies may contribute to future studies on memory sharing practices in different cultures via establishing a theoretical and methodological basis.

\section{REFERENCES}

Conway, M. A. ve Rubin, D. C. (1994). The structure of autobiographical memory. A. F. Collins, S. E. Gathercole, M. A. Conway ve P. E. Morris (Eds.), Theories of memory içinde (103-137). Hove: Lawrence Erlbaum Associates, Publishers.

Nelson K. \& Fivush, R. (2004). The cmergence of autobiographical memory: A social cultural developmental theory. Psychological Review, 111(2), 486-511.

Bohanek, J. G., Fivush, R., Zaman, W., Lepore, C. E, Merchant, S., \& Duke, M. P. (2009). o

Narrative interaction Oin family dinnertime conversations. Merrill-Palmer O Ouarterly, 55(4), o 488 -515. doi:10.1353/mpg.0.0031. 